\title{
THE ENMAP MISSION: FROM OBSERVATION REQUEST TO DATA DELIVERY
}

\author{
Martin Habermeyer ${ }^{1)}$, Nicole Pinnel ${ }^{1)}$, Tobias Storch ${ }^{1)}$, Hans-Peter Honold ${ }^{2)}$, Paul Tucker ${ }^{2)}$, Luis \\ Guanter $^{3)}$, Karl Segl ${ }^{3)}$, Sebastian Fischer ${ }^{4)}$ \\ 1) DLR EOC, Münchner Str. 20, 82234 Weßling, Germany \\ 2) OHB System AG, Manfred-Fuchs-Str. 1, 82234 Weßling, Germany \\ 3) Helmholtz Centre Potsdam (GFZ), Telegrafenberg A17, 14473 Potsdam, Germany \\ 4) DLR Space Administration, Königswinterer Str. 522-524, 53227 Bonn, Germany \\ ${ }^{*}$ martin.habermeyer@dlr.de
}

\begin{abstract}
EnMAP (Environmental Mapping and Analysis Program, www.enmap.org) is a German, Earth observing, imaging spectroscopy, spaceborne mission planned for launch in 2020. The data products will cover the spectral range from $420 \mathrm{~nm}$ to $2450 \mathrm{~nm}$ with a spectral sampling distance between 5 and $12 \mathrm{~nm}$ with an expected signal-to-noise-ratio of 400:1 in the visible near-infrared and 180:1 in the shortwave infrared parts of the electro-magnetic spectrum. The resulting images will cover an area of $30 \mathrm{~km}$ in the acrosstrack direction with a ground sampling distance of $30 \mathrm{~m}$. The across-track tilt-capability of $30^{\circ}$ enables revisit times of less than four days. The resulting data products will be freely available to the scientific user community for measuring, deriving, and analyzing diagnostic parameters, which describe vital processes on the Earth's surface comprising agriculture, forestry, soil and geological environments, as well as coastal zones and inland waters. This work concentrates on the description of activities performed and facilities involved for the preparation of these products. It starts out by the description of the User Portals for observation requests and acquisition planning, touches the aspects of creating the time-lines, the commanding and controlling of the satellite, the downlink of the telemetry and payload data, the design of the processing chain and the archiving of data plus a set of activities flanking the above for the provision of high-quality data products.
\end{abstract}

Index Terms - Imaging Spectroscopy, Remote Sensing Satellite, EnMAP, User Portal, Processing Chain

\section{INTRODUCTION}

EnMAP (Environmental Mapping and Analysis Program, enmap.org) [1] is a scientific mission for measuring, deriving, and analyzing diagnostic parameters, which describe vital processes on the Earth's surface comprising agriculture, forestry, soil and geological environments, as well as coastal zones and inland waters. Open access to all products will be granted to the international user community. The launch is scheduled for 2020 .

The OHB System AG is responsible for realizing the space segment and the Earth Observation Center (EOC), together with the German Space Operations Center (GSOC), both of the German Aerospace Center (DLR) is responsible for establishing and operating the ground segment [2]. The DLR Space Administration covers the mission management.

In Section 2 an overview of the specification parameters of the EnMAP Mission regarding the mission is given. Available data products are addressed in Section 3. An overview of the tasks performed from the moment when the scientist places an acquisition request or orders already acquired data until the moment where the data can be picked up from a delivery point is given in Section 4. This comprises controlling and commanding the satellite using multi-mission infrastructures as well as data reception, hyperspectral data processing including calibration, data archiving, data dissemination, and provision of webinterfaces to the international user community.

\section{MISSION SPECIFICATIONS}

The mission relies on a prism-based dual-spectrometer [2]. The VNIR spectrometer covers the spectral range from 420 $\mathrm{nm}$ to $1000 \mathrm{~nm}$ with a spectral sampling distance between $4.8 \mathrm{~nm}$ and $8.2 \mathrm{~nm}$. The SWIR spectrometer covers the spectral range from $900 \mathrm{~nm}$ to $2450 \mathrm{~nm}$ with a spectral sampling distance between $7.4 \mathrm{~nm}$ and $12.0 \mathrm{~nm}$. The total number of spectral bands is 262 with a spectral oversampling rate of about 1.2 for both instruments. A signal-to-noise ratio of 400:1 at $495 \mathrm{~nm}$ and 150:1 at 2200 $\mathrm{nm}$ is expected (at reference radiance level, which is defined by $30 \%$ surface albedo, $30^{\circ}$ Sun zenith angle, ground at sea level, and $40 \mathrm{~km}$ visibility with rural atmosphere). The radiometric resolution is 14 bits. Each detector array has 1000 valid pixels in spatial direction with an instantaneous field-of-view of 9.5 arcsec. The resulting geometric resolution is $30 \mathrm{~m} \times 30 \mathrm{~m}$ and the swath width (across-track) 


\begin{tabular}{|c|c|}
\hline \multicolumn{2}{|c|}{ Mission Parameters } \\
\hline Spectral range & $420-2450 \mathrm{~nm}$ \\
\hline Ground sampling distance & $30 \mathrm{~m}$ \\
\hline Swath width & $30 \mathrm{~km}$ \\
\hline Orbit & $\begin{array}{l}\text { sun-synchronous } \\
11: 00 \mathrm{~h} \pm 17 \text { min local time } \\
\text { descending node, } \\
\text { altitude: } 652 \mathrm{~km} \\
398 \text { revolutions in } 27 \text { days }\end{array}$ \\
\hline Daily coverage & $5000 \mathrm{~km}$ \\
\hline \multicolumn{2}{|c|}{ Instrument Parameters } \\
\hline Imaging principle & Pushbroom prism \\
\hline Number of Bands & 262 \\
\hline Spectral range & $\begin{array}{l}\text { VNIR: } 420-1000 \mathrm{~nm} \\
\text { SWIR: } 900-2450 \mathrm{~nm}\end{array}$ \\
\hline Spectral sampling distance & 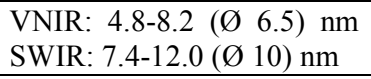 \\
\hline Spectral Oversampling & 1.2 \\
\hline SNR@ reference radiance & $\begin{array}{l}\text { VNIR: 400:1@ } 995 \mathrm{~nm} \\
\text { SWIR: 150:1@2200nm }\end{array}$ \\
\hline Spectral stability & $\begin{array}{l}\text { VNIR: } 0.5 \mathrm{~nm} \\
\text { SWIR: } 1.0 \mathrm{~nm}\end{array}$ \\
\hline $\begin{array}{l}\text { Radiometric calibration } \\
\text { accuracy }\end{array}$ & $<5 \%$ \\
\hline Radiometric resolution & 14 bits \\
\hline Instantaneous field of view & $9.5 \operatorname{arcsec}$ \\
\hline $\begin{array}{l}\text { Geometric pointing } \\
\text { accuracy }\end{array}$ & $\begin{array}{l}100 \mathrm{~m} \text {, improved to } \sim 30 \mathrm{~m} \\
\text { (using Ground Control } \\
\text { Points) }\end{array}$ \\
\hline Target revisit time & $<4$ days \\
\hline
\end{tabular}

Table 1. Mission and Instrument Parameters

is $30 \mathrm{~km}$ as the satellite is operating from an altitude of $652 \mathrm{~km}$. EnMAP has a repeat cycle of 398 revolutions in 27 days. The revisit time is less than four days, as the platform has a tilt-capability of $30^{\circ}$. The local time of descending node is 11:00 hrs $\pm 17 \mathrm{~min}$. At most $5000 \mathrm{~km}$ (across-track) can be recorded per day. Calibration equipment, especially a doped sphere with spectral features and a full aperture diffuser for Sun calibrations allows achieving a spectral accuracy of better

than $0.5 \mathrm{~nm}$ in VNIR and $1.0 \mathrm{~nm}$ in SWIR as well as a radiometric accuracy of better than 5\%. A geometric accuracy of $100 \mathrm{~m}$ is achieved - improved by on-ground processing to $30 \mathrm{~m}$ with respect to a reference image.

The resulting mission and instrument-related parameters are shown in Table 1.

\section{AVAILABLE DATA PRODUCTS}

The following EnMAP data products will be made available for the scientific user:

- Level 0: Time-tagged instrument raw data with auxiliary information (internal)

- Level 1B: Radiometrically-corrected, spectrallyand geometrically-characterised radiance

- Level 1C: Orthorectified level 1B

- Level 2A: Atmospherically-corrected level 1C Only Level 0 products are archived, other product levels are produced on demand.

The different product levels are discussed in Section 4 and the processing chain is shown in Figure 2.

\section{FROM OBSERVATION REQUEST TO DATA DELIVERY}

The design of the ground segment has been discussed in [3], complemented by a dynamic view on its activities [4]. Here an effort is made to give an overview in the partly subsequent, partly parallel steps performed to provide the user with high-quality data.

\subsection{Observation Requests and Acquisition Planning}

There are two major scenarios of interest for the users. On the one hand users can apply for image acquisitions based on user requests and on the other hand the generation of standardized products based on acquisitions or archive orders by users.

For the scientific user a state-of-the-art web-portal is provided where the user's proposals observation and calibration requests are specified and managed. Figure 1 shows a view of the User Portal, where the user is supported in the planning of an observation request. Further, the scientific review is supported at that point and Help-Desk functionality is provided. For archive orders a generic tool adopted for the EnMAP mission is used. The observation requests are then arranged together with the data downlinks, and other planned activities in a conflict-free timeline that does not violate any resource constraints. Availability information for an observation request is then introduced into the User Portal.

\subsection{Controlling and Commanding}

The then planned operations are translated into telecommands and sent to the spacecraft via S-Band at the Ground Station in Weilheim, Germany, in the nominal case with an uplink capability of $4 \mathrm{kBit} / \mathrm{s}$. During a contact also the telemetry data is received with a downlink bandwidth of 32 


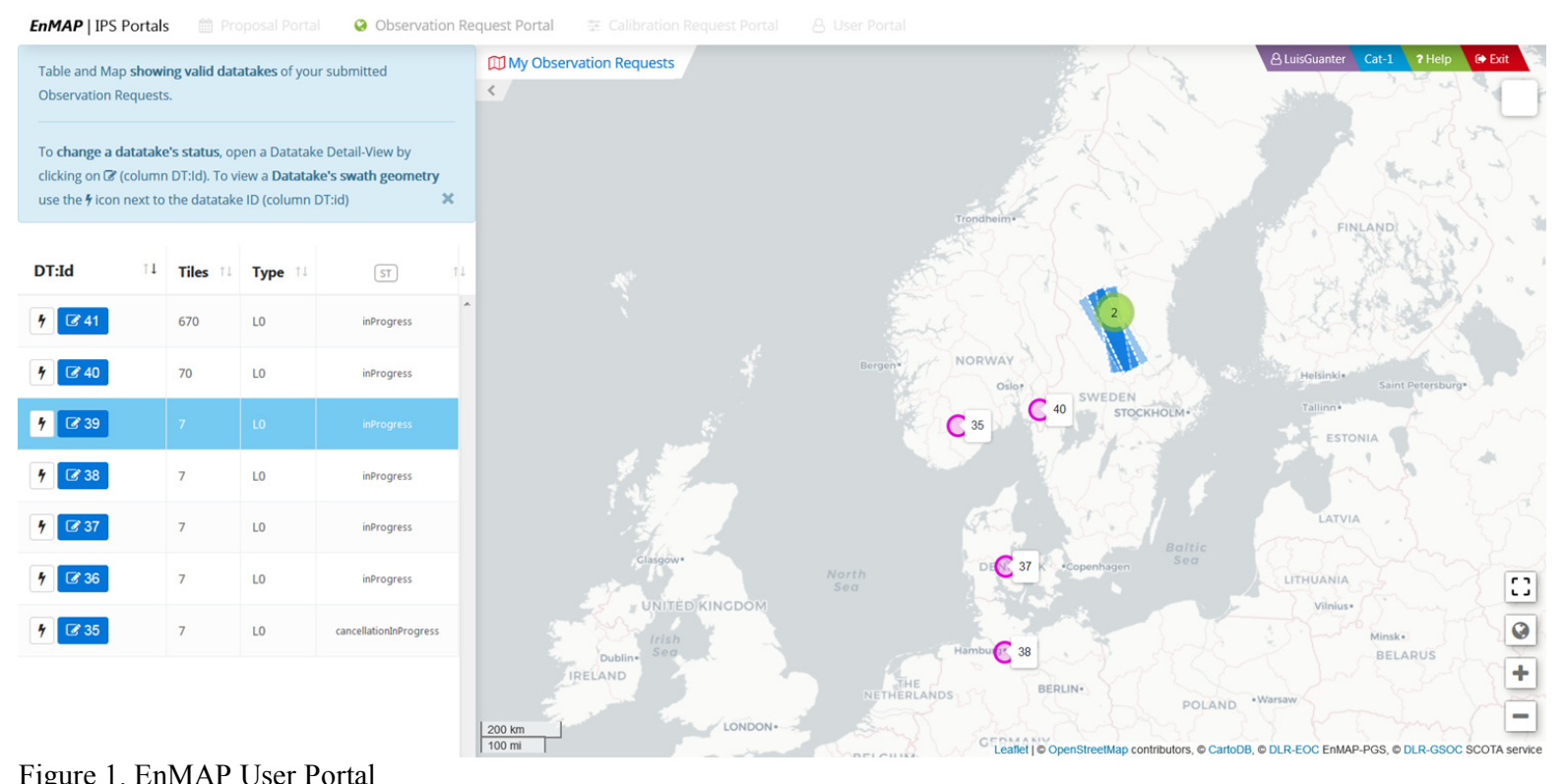

Figure 1. EnMAP User Portal

\subsection{Data Processing}

$\mathrm{kBit} / \mathrm{s}$. For the off-nominal case a world-wide ground station network for telecommanding and telemetry is available. These and further monitoring and control activities are coordinated from the control room situated in Oberpfaffenhofen, Germany. Further data streams are stored and analyzed and simulations are performed. This is flanked by measures to determine orbit and attitude data as well as orbit prediction based on relevant on-board data, such as data from the Global Positioning System and on-ground measurements such as ranging and angle tracking.

The imagery data then is acquired from space and recorded aboard the satellite with the parameters specified in Section 2 and stored until further download.

\subsection{Data Reception and Preparation}

The payload data is received by the Ground Station Neustrelitz, Germany, via X-Band and a downlink capacity of $320 \mathrm{Mbit} / \mathrm{s}$. The data consists of the spectrometer data as well as auxiliary files and data from the attitude and orbit control system. All supplemental information for the hyperspectral images generation such as spectral, radiometric, and geometric calibration and reference tables as well as orbit and attitude products are generated from this datastream.

Archive products and spectrally, radiometrically, geometrically and atmospherically corrected hyperspectral images are generated on an operational basis. The products available are specified in Section 3. An overview of the processing chain is given in Figure 2. It comprises processor elements to generate quality information, quicklooks, water-land masks, cloud masks, tiling, correction of known effects like odd-even and nonuniformity, conversion to physical at-sensor radiance values, direct geo-referencing with image-to-image adjustment and atmospheric corrections separated for land and water surface applications. A detailed description of the EnMAP processing chain is available in [5].

\subsection{Archiving and Dissemination}

Data Dissemination is provided by a multi-mission facility providing distributed archiving and dissemination of data products to the user segment through an online interface.

\subsection{Instrument Monitoring, Calibration and Quality} Control

Besides the above activities the tasks of the ground segment are flanked by analysis of the long-term behavior and malfunctions of the instrument estimated based on 


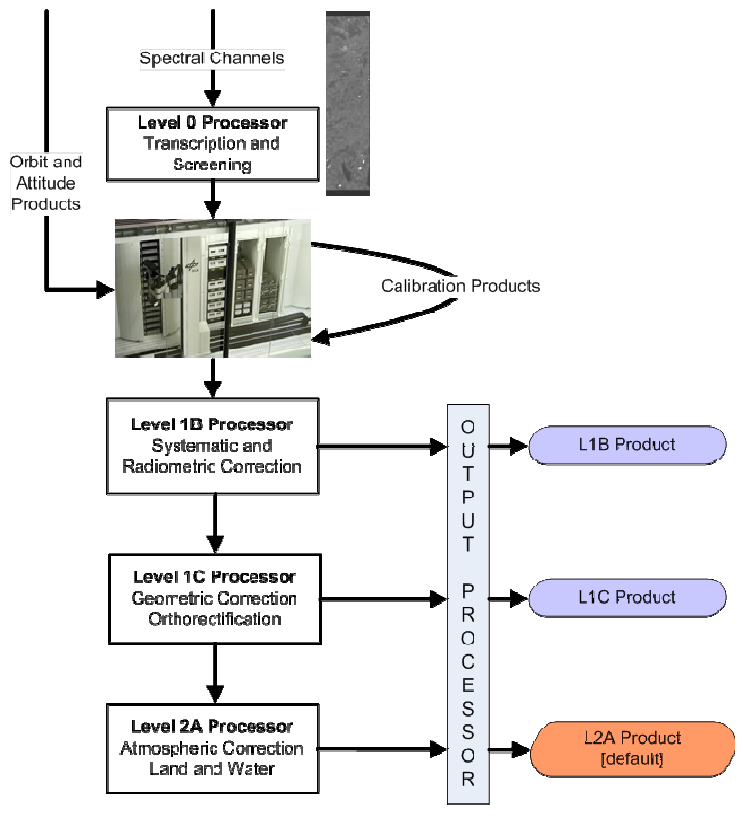

Figure 2. EnMAP Processing Chain

housekeeping telemetry, calibration data, and Earth measurements. Furthermore calibration and reference tables based on dark current measurements, measurements of internal sources such as lamps and Light-Emitting Diodes, and Sun measurements for spectral and radiometric characterization and calibration are generated allowing the accurate calibration of the instrument. Besides that geometric calibration and reference tables based on different on-ground measurements are generated. Additionally, the accuracy of all processing levels of hyperspectral data is assessed to detect calibration or processing errors.

\section{CONCLUSIONS}

Based on the Design of the EnMAP Mission and the mission's and instrument's parameters and the available data products an overview of the tasks performed from observation request until data dissemination has been given. This comprises controlling and commanding the satellite using multi-mission infrastructures as well as data reception, hyperspectral data processing, including calibration, data archiving, data dissemination as well as accompanying activities such as Instrument Monitoring, Calibration and Quality Control.

\section{ACKNOWLEDGEMENTS}

Supported by the DLR Space Administration with funds of the German Federal Ministry of Economic Affairs and Technology on the basis of a decision by the German Bundestag (50 EE 0850).

\section{REFERENCES}

[1] Guanter, L., H. Kaufmann, K. Segl, S. Förster, C. Rogass, S. Chabrillat, T. Küster, A. Hollstein, G. Rossner, C. Chlebek, C. Straif, S. Fischer, S. Schrader, T. Storch, U. Heiden, A. Müller, M. Bachmann, H. Mühle, R. Müller, M. Habermeyer, A. Ohndorf, J. Hill, H. Buddenbaum, P. Hostert, S. van der Linden, P.J. Leitao, A. Rabe, R. Doerffer, H. Krasemann, H. Xi, W. Mauser, T. Hank, M. Locherer, M. Rast, K. Staenz, and B. Sang, "The EnMAP Spaceborne Imaging Spectroscopy Mission for Earth Observation“, Remote Sensing, 7(7), pp. 8830-8857, 2015.

[2] Kaufmann, H., B. Sang, T. Storch, K. Segl, S. Foerster, L. Guanter, M. Erhard, B. Heider, S. Hofer, H.-P. Honold, B. Penné, M. Bachmann, M. Habermeyer, A. Müller, R. Müller, M. Rast, K. Staenz, C. Straif, and C. Chlebek, "Environmental Mapping and Analysis Program - A German Hyperspectral Mission", Optical Payloads for Space Missions, pp. 161-182, 2016.

[3] Habermeyer, M., T. Storch, S. Eberle, C. Makasy, S. Maslin, A. de Miguel, K.-D. Mißling, H. Mühle, R. Müller, S. Engelbrecht, J. Gredel, U. Heiden, 2010. Ground Segment Design of the EnMAP Hyperspectral Satellite Mission. In: Hyperspectral Workshop 2010, Frascati, Italy.

[4] Storch, T., M. Habermeyer, S. Eberle, H. Mühle, and R. Müller, "Towards a Critical Design of an Operational Ground Segment for an Earth Observation Mission”, Journal of Applied Remote Sensing, 7(1), pp. 1-12, 2013.

[5] Müller, R., M. Bachmann, C. Makasy, A. de Miguel, A. Müller, A. Neumann, G. Palubinskas, R. Richter, M. Schneider, T. Storch, T. Walzel, H. Kaufmann, L. Guanter, K. Segl, T. Heege, and V. Kiselev, "The Processing Chain and Cal/Val Operations of the Future Hyperspectral Satellite Mission", IEEE Aerospace Conference Proceedings, 2010. 